\title{
SPECTRAL AND TIME-RESOLVED STUDIES OF GREEN $\mathrm{Cs}_{2}$ FLUORESCENCE
}

\author{
B. Bieniak, M. Glódź, W. Jastrzębsiki and J. Szonert \\ Institute of Physics, Polish Academy of Sciences \\ Al. Lotników 32/46, 02-668 Warszawa, Poland
}

(Received December 29, 1992; revised version April 30, 1993)

The origin and dynamic properties of the green fluorescence of $\mathrm{Cs}_{2} \mathrm{ex}$ cited by laser lines in the $457-488 \mathrm{~nm}$ range are studied. Emphasis is placed on the analysis of the 501-527 $\mathrm{nm}$ range. The identified fluorescence line progressions are attributed to the $E^{\prime}(3)^{1} \Pi_{\mathrm{u}} \rightarrow X^{1} \Sigma_{\mathrm{g}}^{+}$transition. An extension of the attractive branch of the $E^{\prime}(3)^{1} \Pi_{\mathrm{u}}$ potential towards longer internuclear distances is reconstructed by the semi-classical method. A narrow feature at $522 \mathrm{~nm}$ is found to be connected with a minimum of the difference potential. The lifetime values are measured. The multicomponent fluorescence decays are interpreted as evidence of perturbations of the $E^{\prime}(3)^{1} I I_{\mathrm{u}}$ state by a number of bound and repulsive states of different symmetry. The predissociation rates are estimated.

PACS numbers: 33.20.Kf, 34.50.Gb

\section{Introduction}

In this work we have studied the origin and dynamic properties of the green fluorescence of $\mathrm{Cs}_{2}$ excited by laser lines in the $457-488 \mathrm{~nm}$ range.

In opposition to the lower states of $\mathrm{Cs}_{2}$ which are both experimentally (Ref. [1] and references therein) and theoretically [2] rather well determined, the higher states attainable by absorption in the green or blue range are less known. The absorption band centered at $480 \mathrm{~nm}$ [3-6] is accompenied at its long wavelength limit by a distinct peak at $522.3 \mathrm{~nm}$. Tellinghuisen and Moeller [7] assumed that both structures originate from a single electronic transition and that the $522.3 \mathrm{~nm}$ peak corresponds to the minimum in the difference potential. Excitation caused by blue laser light produces a strong green emission $[8,9]$. On the long wavelength side the spectra are terminated with a narrow structure which, under low resolution, has the appearance of a peal at $522.3(3) \mathrm{nm}$. Its position is practically independent of excitation wavelength ([9], see also Fig. 5). In the present paper attention will be paid to an analysis of this spectral feature of fluorescence. 
In high resolution experiments Amiot et al. [10, 11] and Amiot [12] singled out two states excited by green and blue argon ion laser lines, $E(3)^{1} \Sigma_{u}^{+}$ and $E^{\prime}(3)^{1} \Pi_{\mathrm{u}}$, which correlate asymptotically with $\left(6 s^{2} S_{1 / 2}+7 s^{2} S_{1 / 2}\right)$ [1] and $\left(6 s^{2} S_{1 / 2}+7 p^{2} P_{1 / 2}\right)$ [12] atomic states, respectively (see Fig. 1). Potential wells

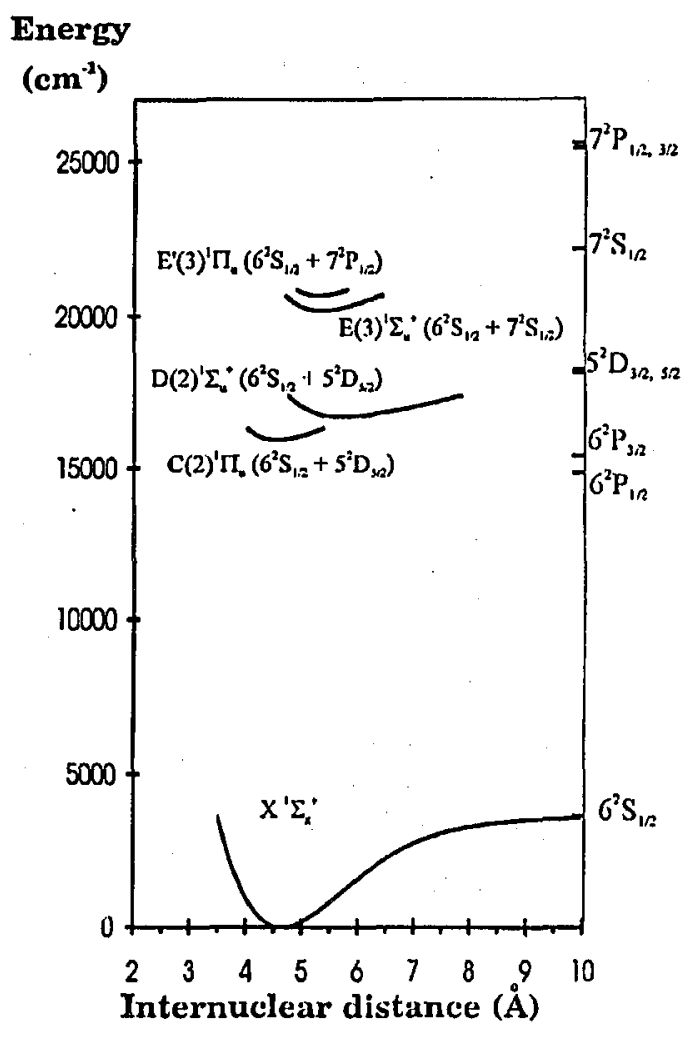

Fig. 1. Experimentally determined potential energy curves of selected electronic states of $\mathrm{Cs}_{2}$.

were determined for $E(3){ }^{1} \Sigma_{\mathrm{u}}^{+}$up to $v^{\prime} \leq 20$ and for $E^{\prime}(3)^{1} I_{\mathrm{u}}$ up to $v^{\prime} \leq 6$. $E^{\prime}(3)^{1} \Pi_{\mathrm{u}}$ is the highest among the identified states of $\mathrm{Cs}_{2}$. Heterogeneous perturbations and, for $v^{\prime}>6$, also indications of homogencous perturbations were found for this state [12]. Upon pulsed excitation with blue light Collins et al. $[13,14]$ observed in a photolytic study relatively strong production of $5^{2} D_{3 / 2,5 / 2}$ atoms, reaching a maximum at $474 \mathrm{~nm}$, and a small amount of $6{ }^{2} P_{1 / 2,3 / 2}$ atoms. Wu and Huennekens [15] found that for exciting wavelength $\lambda_{\text {las }}=465.8 \mathrm{~nm}$ (of a cw Ar ${ }^{+}$ laser) predissociation to $7^{2} S_{1 / 2}$ is comparable or even stronger than to $5^{2} D_{3 / 2,5 / 2}$. Lifetime data on $\mathrm{Cs}_{2}$ for the spectral region of interest are scarce and obtained under an assumption of single-exponential decay. Baumgartner et al. [16] used the phase shift technique, a very broad observation range (glass-edge filter), 
and excitation with argon ion laser and determined $\tau\left(\lambda_{\text {las }}=488 \mathrm{~nm}\right)=27 \mathrm{~ns}$, $\tau\left(\lambda_{\text {las }}=476.5 \mathrm{~nm}\right)=\tau\left(\lambda_{\text {las }}=472.7 \mathrm{~nm}\right)=12 \mathrm{~ns}, \tau\left(\lambda_{\text {las }}=457.9 \mathrm{~nm}\right)=6.4 \mathrm{~ns} . W \mathrm{Wu}$ and Huennekens [15] used the same method and observation at $500 \mathrm{~nm}$ with $6 \mathrm{~nm}$ spectral slitwidth and obtained $\tau\left(\lambda_{\text {las }}=488 \mathrm{~nm}\right)=42 \mathrm{~ns}, \tau\left(\lambda_{\text {las }}=465.8 \mathrm{~nm}\right)=$ $28 \mathrm{~ns}$. Höning et al. [17] reported preliminary results for lifetimes: $\tau=17 \mathrm{~ns}$ for the $E(3)^{1} \Sigma_{\mathrm{u}}^{+}$state and $\tau=8 \mathrm{~ns}$ for the $E^{\prime}(3)^{1} I_{\mathrm{u}}$ state.

This paper brings some new spectral and lifetime data concerning $\mathrm{Cs}_{2}$ excited by blue light. Some of the results have been communicated earlier $[9,18-20]$. The paper is organized as follows. In Sec. 2 experimental arrangements are described. In Sec. 3 spectral studies are reported with a conclusion that the $E^{\prime}(3)^{1} \Pi_{\mathrm{u}}$ state is the origin of the observed green fluorescence, including the structure at $522 \mathrm{~nm}$. Extension of the potential of the $E^{\prime}(3)^{1} \Pi_{\mathrm{u}}$ state towards longer internuclear distances is established. The difference potential is found to reach a minimum in this region. In Sec. 4 lifetime studies are presented and discussed. Predissociation rates are estimated. Summary of the results is given in Sec. 5 .

\section{Experimental arrangements}

The experiments were performed either with a pulsed dye laser or with an argon ion laser. A system with a dye laser enabled broad tuneability. By employing an argon ion laser in $\mathrm{cw}$ or in mode-locked regime an increased resolution in spectral- and/or time-domain was achieved although only at a few available excitation wavelengths.

\subsection{Syslem with a pulsed dye laser}

A block diagram of the apparatus is shown in Fig. 2. A two-stage $\mathrm{N}_{2}$ laser-pumped dye laser provided pulses of 3 ns duration. The laser linewidth was $6-10 \mathrm{~cm}^{-1}$ and laser wavelength was calibrated with absolute accuracy of $5 \mathrm{~cm}^{-1}$. Cesium vapor was produced in a carefully prepared Corning 1720 glass-made cell

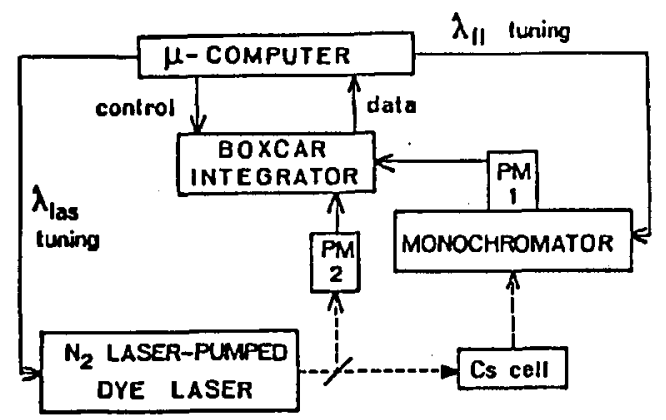

Fig. 2. A block diagram of the setup for the pulsed dye liser experiments. PM1 and PM2 are photomultipliers. 
placed in a double chamber oven. The bottom part was kept at a temperature $T_{1}$ a few degrees lower than the upper part temperature $T_{2}$. The laser beam was directed into the upper part of the cell. The fluorescence observed at $90^{\circ}$ to the laser beam was dispersed with the monochromator (spectral slitwidth $20-80 \mathrm{~cm}^{-1}$ depending on experiment) and detected with a plotomultiplier (RCA 4832). In order to enable one to normalize fuorescence signals to the exciting light intensity, the laser radiation level was monitored. Both signals, corresponding to intensities of the fluorescence and laser light, were directed to a boxcar averager. The scanning of the laser and the monochromator was performed with stepper motors. In order to control the operation of the boxcar and of the stepper motors and for signal averaging, storage and processing a microcomputer was used [21]. With this system fluorescence and excitation spectra (see Sec. 3.1) and lifetimes (Sec. 4.1) were obtained.

\subsection{Syslems based on an argon ion laser}

A scheme of the apparatus for spectral studies which are described in Sec. 3.2 is shown in Fig. 3. A multimode cw argon ion laser (with linewidth of $0.2 \mathrm{~cm}^{-1}$ ) was used to excite the cesium vapor produced in a heat-pipe oven. The oven was operated in the temperature range $T=598 \div 613 \mathrm{~K}$. Fluorescence was observed through a monochromator with spectral slitwidth typically $0.3 \div 3 \mathrm{~cm}^{-1}$. A single photon counting signal was detected with a cooled photomultiplier (RCA C31034) and a ratemeter. For each selected $\lambda_{\text {las }}$ the monochromator was continuously scanned through the fluorescence spectrum.

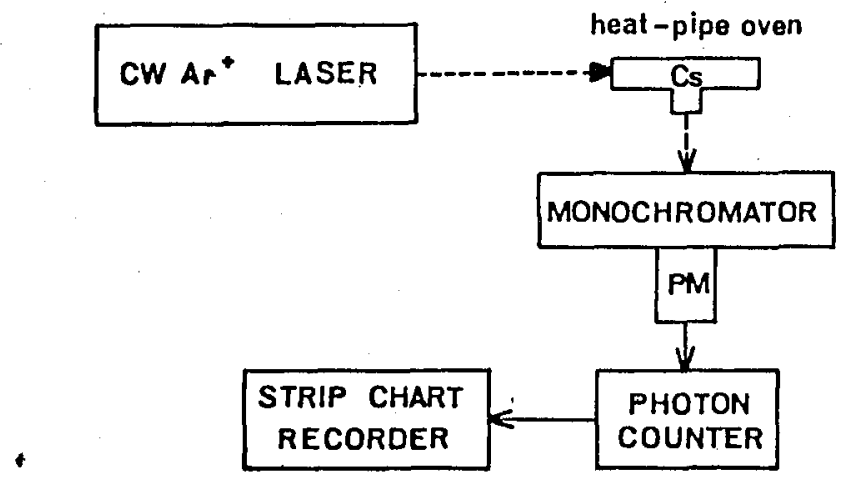

Fig. 3. Experimental arrangement used for the expcriment with a $\mathrm{cw}$ argon ion laser.

For lifetime measurements (see Sec. 4.2) the argon ion laser was mode-locked and cavity-dumped. The scheme of the apparatus is shown in Fig. 4. The heat-pipe oven was operated in the true heat-pipe regime. Time-resolved fluorescence was observed at several selected $\lambda_{\mathrm{f}}$ with spectral resolution of $6 \mathrm{~cm}^{-1}$. Decay signals were detected with the technique of single photon counting in delayed coincidence. 


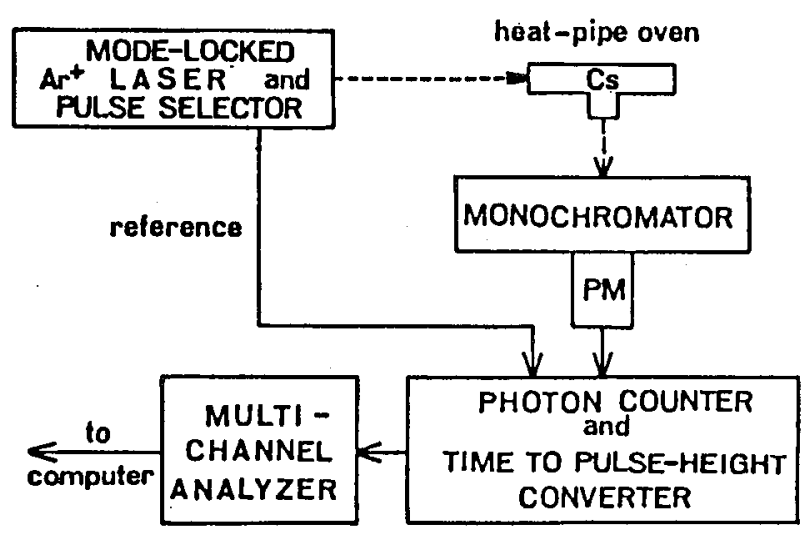

Fig. 4. Experimental arrangement used in the lifetime measurements described in Sec. 4.2.

\section{Spectral studies}

\subsection{Spectra oblained with the dye laser system}

\subsubsection{Fluorescence spectra}

The fluorescence spectra were recorded (for the apparatus see Fig. 2) at constant $\lambda_{\text {las }}$ by scanning the monochromator, with spectral resolution of $30 \mathrm{~cm}^{-1}$, within the $\lambda_{\mathrm{f}}=501 \div 527 \mathrm{~nm}$ range. The laser linewidth was $10(2) \mathrm{cm}^{-1}$. The cell temperature $T_{2}$ was $575 \mathrm{~K}$.

Figure 5 shows a selection of spectra, excited with wavelengths in the range of 457-488 nm. In each spectrum a distinct band about 2-4 nm FWIIM wide, with a maximum at $522 \mathrm{~nm}$, can be seen. Its position is nearly independent of $\lambda_{\text {las }}$ and its intensity dominates that of the accompanying bands for most of the range of $\lambda_{\text {las }}$. At the red-end all spectra weaken rapidly, whereas the patterns at the blue-side vary significantly. For the several shortest settings of $\lambda_{\text {las }}$ a pattern spanning the range $\lambda_{\mathrm{f}}=508 \div 520 \mathrm{~nm}$ is seen, which will hereafter be called weak bands. With increasing $\lambda_{\text {las }}$ a structure called hereafter strong bands builds up.

Despite low resolution, information on energies of levels was derived. If absorbing levels are assumed to be close to the minimum of the $X^{1} \Sigma_{\mathrm{g}}^{+}$potential and the energy difference between the exciting and fluorescence photons $(\Delta E=$ $\left.E_{\text {las }}-E_{\mathrm{f}}\right)$ is considered, then the terminating levels of fluorescence should also belong to this state. With the known molecular constants [22] the intervals between levels $\left(v^{\prime \prime}, J^{\prime \prime}\right)$ and $\left(v^{\prime \prime}+1, J^{\prime \prime}\right)$ can be compared with the observed spacings.

For the strong bands, which are typically spaced by $29-35 \mathrm{~cm}^{-1}$, the terminating levels of fluorescence span the range $1800-2400 \mathrm{~cm}^{-1}$ (equivalent to $v^{\prime \prime}=28-63$, if $J^{\prime \prime}$ is assumed to be in the most probable range 100-250). Since $\Delta E=1400 \div 1800 \mathrm{~cm}^{-1}$ for the spectra with the best developed strong bands, the absorbing levels extend in the $0-1000 \mathrm{~cm}^{-1}$ range.

It is noted that in the well-represented weak bands in the $\lambda_{\text {las }}=459.7 \mathrm{~nm}$ spectrum, spacings of $50-52 \mathrm{~cm}^{-1}$ exceed the distances of $40(2) \mathrm{cm}^{-1}$. between 


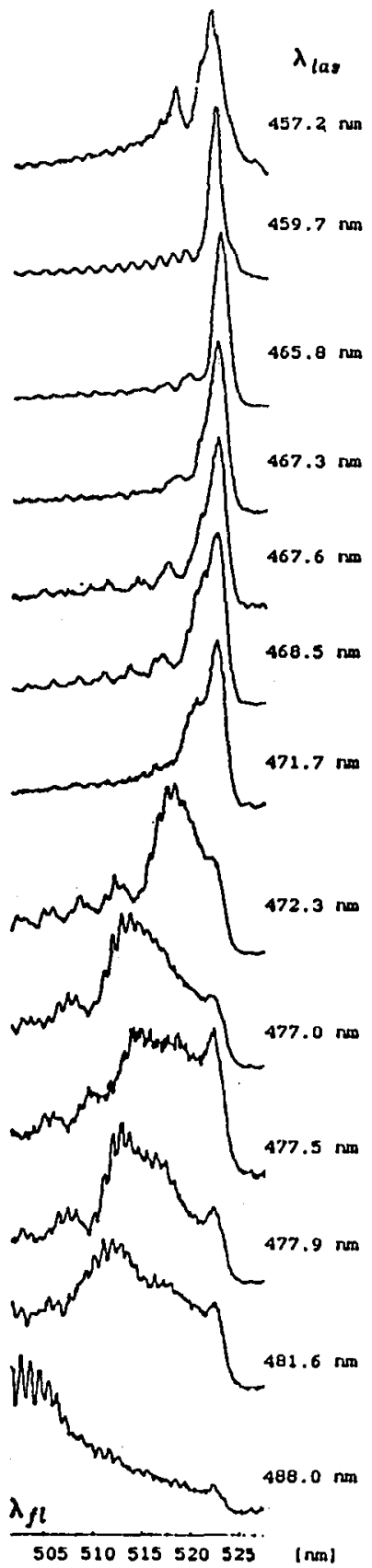

Fig. 5. Fluorescence spectra of $\mathrm{Cs}_{2}$ in the region of 501-527 $\mathrm{nm}$ recorded for different excitation wavelengths $\lambda_{\text {las }}$. The spectra are normalized to the same plot size. 
the lowest levels of $X^{1} \Sigma_{\mathrm{g}}^{+}$. Ilowever, such spacings may originate in dominant progressions for which due to the Franck-Condon factors every second line is weak or missing. If so, the terminating levels for fluorescence composing the weak bands are separated by $25-26 \mathrm{~cm}^{-1}$, which situates these levels in the $2770-2950 \mathrm{~cm}^{-1}$ $\left(v^{\prime \prime}=65 \div 77\right)$ range. Accordingly, since $\Delta E=1740 \div 2450 \mathrm{~cm}^{-1}$ the absorbing levels lie within $300-1200 \mathrm{~cm}^{-1}$ range. With excitation of several $v^{\prime}$ levels and broad band observation one may expect that effects of the Franck-Condon factors would be washed out. But, in favorable cases, a number of progressions with similar spacings can dominate in a spectral region of interest tlus justifying the performed analysis. Indeed spacings of progressions belonging to the strong and weak bands determined during an analysis of better resolved spectra (Sec. 3.2) agree with those presented above.

\subsubsection{Excitation spectra}

The wavelength-selective excitation spectra were oblained by scanning the laser light in the $458-488 \mathrm{~nm}$ range while the fluorescence was observed at a fixed $\lambda_{\mathrm{f}}$ selected from the range of 508.9-523.2 nm. Excitation spectra contain information on vibrational structure of the absorbing state. The conditions were similar to those in Sec. 3.1.1 except for lower temperature of the cell $\left(T_{2}=564 \mathrm{~K}\right)$.

A representative set of spectra is depicted in Fig. 6. For $\lambda_{\text {las }}=458 \div 467.4 \mathrm{~nm}$ the signals are weak and only for $\lambda_{\mathfrak{l}} \geq 521.6 \mathrm{~nm}$ the more intense fluorescence is observed. The bands spaced by $c a .40 \mathrm{~cm}^{-1}$ can be recognized. Ilence, the lowest levels of $X^{1} \Sigma_{\mathrm{g}}^{+}$are involved in absorption leading to this fluorescence. For $\lambda_{\text {las }}=467.4 \div 476.2 \mathrm{~nm}$ bands spaced by $20 \div 21 \mathrm{~cm}^{-1}$ appear, and are well resolved in the $\lambda_{\mathrm{f}}=516.1,519.3$ and $520.9 \mathrm{~mm}$ spectra. Such intervals are expected for higher levels of $X^{1} \Sigma_{\mathrm{g}}^{+}$, which are unlikely to participate in absorption (compare Sec. 3.1.4). Of the two states $E(3)^{1} \Sigma_{\mathrm{u}}^{+}$and $E^{\prime}(3)^{1} I I_{\mathrm{u}}$, assigned $[11,12]$ in the region relevant to the present experiment, the energy considerations point out to the state $E^{\prime}(3)^{1} \Pi_{\mathrm{u}}$ as the one from which the fluorescence is being observed. Its lowest levels are distanced by $29 \mathrm{~cm}^{-1}$, and for ligher levels the spacings presumably reach $20 \mathrm{~cm}^{-1}$ or less. Therefore, the discussed pattern could result from the superimposition of structures of the $X^{1} \Sigma_{\mathrm{g}}^{+}$state, spaced by $40(2) \mathrm{cm}^{-1}$ and those spaced by $20(1) \mathrm{cm}^{-1}$ expected for higher levels of the excited state $E^{\prime}(3)^{1} \Pi_{\mathrm{u}}$.

\subsubsection{Time-resolved spectra}

Time-resolved fluorescence- and wavclength-selective excitation-spectra were registered for selected excitation and observation wavelengths, respectively. Each spectrum was measured with a narrow $700 \mathrm{ps}$ stationary gate delayed against the maximum of the exciting laser pulse, with the origin of the time scale corresponding to this maximum. Delays of up to $20 \mathrm{~ns}$ were selected. The strongest signal is observed immediately (within $2 \mathrm{~ns}$ ) after the laser pulse maximum and the general pattern of the spectra remains almost delay-independent.

We conclude that direct rather than sensitized fluorescence is observed. 


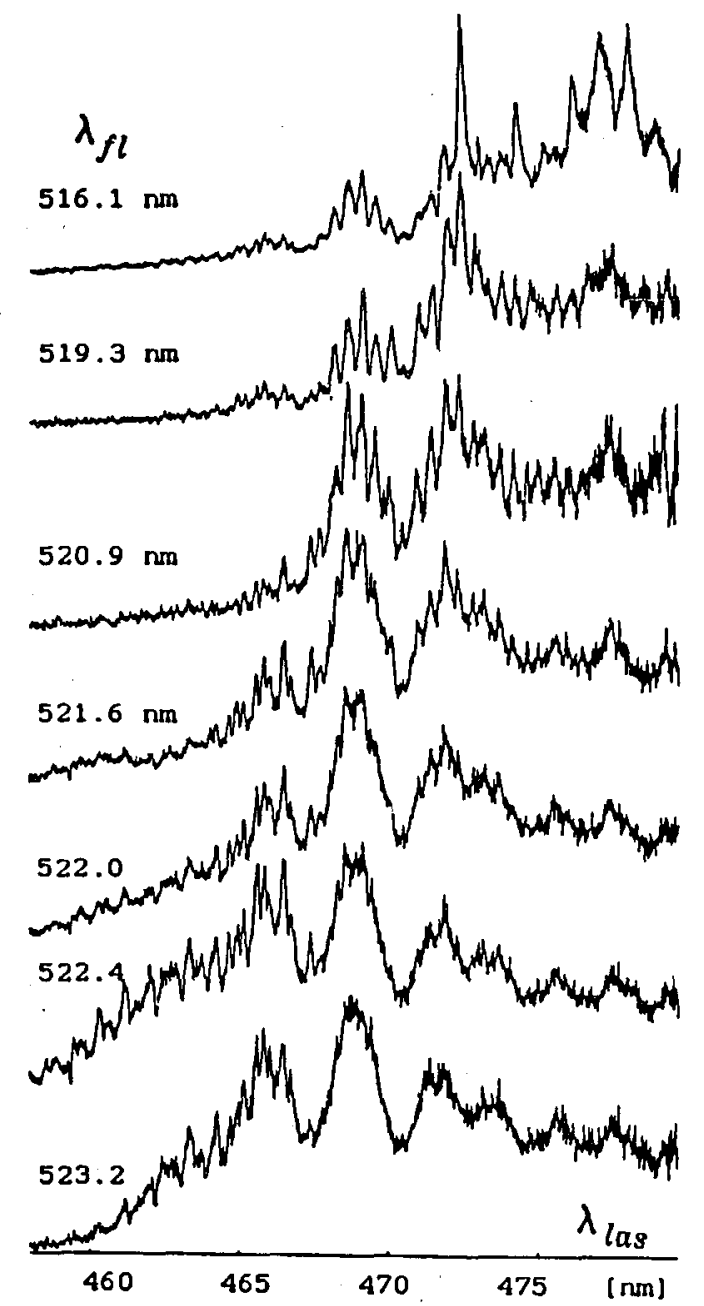

Fig. 6. Wavelength selective excitation spectra recorded for various fluorescence wavelengths $\lambda_{\mathrm{f}}$.

\subsubsection{Temperature dependence of the excitation spectra}

In Secs. 3.1.1, 3.1.2 we assumed that $X^{1} \Sigma_{\mathrm{g}}^{+}$is the absorbing state. A less probable hypothesis which could not have been a priori excluded that loosely bound lowest triplet $x^{3} \Sigma_{\mathrm{u}}^{+}$is involved in absorption. (Absorption from $x^{3} \Sigma_{\mathrm{u}}^{+}$state of $\mathrm{Cs}_{2}$ was observed in $[6,23]$.) The procedure described bclow, aimed at estimating the energy of absorbing levels, is similar to that applied by Gupta et al. [6]. Our modification consists in spectrally selective detection of the fluorescence, instead of monitoring the absorption itself.

The absorption coefficient $\mathcal{K}(\omega)$ of molecules bound with the lower potential 
$V(R)$ can be approximated within the quasistatic approach as $[6,24]$

$$
\mathcal{K}(\omega) \propto n_{\text {at }}^{2} \exp \left[-V\left(R_{\mathrm{S}}\right) / k T_{2}\right],
$$

where $n_{\text {at }}$ is the number density of atoms, $T_{2}$ is the temperature of the vapor, $R_{\mathrm{S}}$ is the Condon (or stationary phase) point at which the transition occurs. A single valued difference potential is assumed and $V\left(R_{\mathrm{S}}\right)$ is measured with respect to its asymptotic (atomic) value.

On assuming that the laser pulse is much shorter than the average lifetime of the excited state and if observation time exceeds the lifetime, then the fluorescence signal $U_{\mathrm{f}}$ is proportional to the number of excited molecules $N$

$$
U_{\mathrm{fl}} \propto N A_{\mathrm{eg}} \tau^{\mathrm{eff}},
$$

where $A_{\text {eg }}$ is the average Einstein coefficient for the observed transitions, $\tau^{\text {eff }}$ is the effective (affected by collisional quenching) lifetime of the excited state. For optically thin vapor $N$ is proportional to the absorption coefficient

$$
N \propto \mathcal{K}\left(\omega_{\text {las }}\right) .
$$

The atomic density in the warmer $\left(T_{2}>T_{1}\right)$ part of the cell is determined by the temperature of liquid cesium in its cooler $\left(T_{1}\right)$ part

$$
n_{\text {at }}=p\left(T_{1}\right) / k T_{2}
$$

where $p\left(T_{1}\right)$ is the pressure of the saturated vapor at the temperature $T_{1}$. From Eqs. (1), (2), (3) and (4) it follows

$$
\ln \left(U_{\mathrm{f}} T_{2}^{2}\right)=-V(R) / k T_{2}+\text { const. }
$$

Weak dependence of $\tau^{\text {eff }}$ on $T_{2}$ is neglected.

The excitation spectra were recorded similarly as in Sec. 3.1.2, with monochromator spectral slitwidth of $60 \mathrm{~cm}^{-1}$, for three wavelengths $\lambda_{\mathrm{f}}=522.4 \mathrm{~nm}$, $516.2 \mathrm{~nm}, 508.9 \mathrm{~nm}$ and for five temperature settings, where $T_{2}$ was varied in the 516-570 K range, while $T_{1}$ was kept constant at $510 \mathrm{~K}$ (it was verified that cesium vapor can be assumed to be optically thin over such a temperature range). For each $\lambda_{\mathrm{f}}$ excitation spectra for five different $T_{2}$ settings were registered. Equation (5) can be considered to be a linear function of $\ln \left(U_{\mathrm{n}} T_{2}^{2}\right)$ with $1 / k T_{2}$, where $V(R)$ is the slope. From a least-squares fit the mean cnergy $V(R)$ of absorbing levels for each excitation $\lambda_{\text {las }}$ (within the 466.2 to $479.4 \mathrm{~mm}$ range) and observation $\lambda_{\mathrm{f}}$ wavelengths was estimated. The results for $\lambda_{11}=522.4 \mathrm{~nm}$ are shown in Fig. 7 . The scatter of points reflects both the measurement uncertainties and different efficiency of excitation for different $\lambda_{\text {las }}$.

The $V(R)$ values obtained for three selected $\lambda_{\mathrm{fl}}$ wavelengths fall within the range of $(-3700)-(-2800) \mathrm{cm}^{-1}, V(R)$ being measured against the dissociation limit. With increasing $\lambda_{\text {las }} V(R)$ tends to rise slightly. The maximum overall uncertainty in the energy of a single point was conservatively estimated to be $400 \mathrm{~cm}^{-1}$. We conclude that since the dissociation energy of $X^{1} \Sigma_{\mathrm{g}}^{+}$amounts to $3649.5 \mathrm{~cm}^{-1}$ [22] while of $x^{3} \Sigma_{\mathrm{u}}^{+}$is $250 \mathrm{~cm}^{-1}$ [23], the triplet state is not involved in absorption and the fluorescence originates in absorption by lower levels of the $X^{1} \Sigma_{\mathrm{g}}^{+}$state (up to about $1000 \mathrm{~cm}^{-1}$, as measured from the bottom of the potential well), which agrees with the estimates of Sec. 3.1.1. 


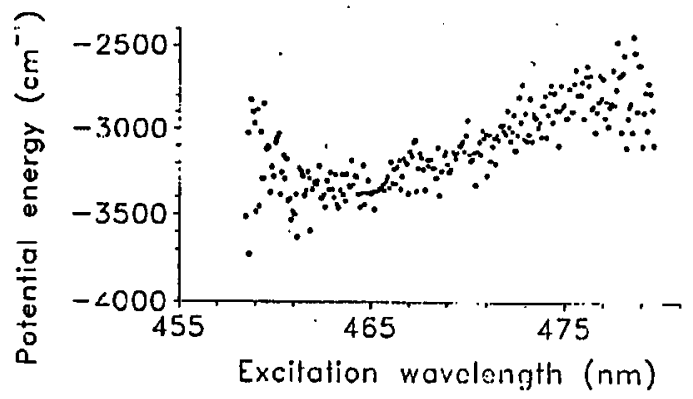

Fig. 7. Potential energy of light absorbing levels, determined from temperature dependence of the Boltzmann population distribution, for the selected fluorescence wavelength $\lambda_{\mathrm{f}}=522.4 \mathrm{~nm}$. Note that vertical scale assumes dissociation energy as origin of the energy scale.

\subsection{Spectral studies wilh selected lines of cw argon ion laser}

Fluorescence spectra, excited consecutively with the following argon ion laser lines: $\lambda_{\text {las }}=457.9,465.8,472.7$ and $476.5 \mathrm{~nm}$ were registered (for the apparatus see Fig. 3) from the anti-Stokes bands to the long-wavelength end of the $522 \mathrm{~nm}$ band. Absolute accuracy of the wave number determination was $\leq 4 \mathrm{~cm}^{-1}$, while the relative accuracy was $\leq 0.4 \mathrm{~cm}^{-1}$. Several progressions of lines were identified. In Fig. 8 specimen portions of the spectra excited with (a) $\lambda_{\text {las }}=457.9 \mathrm{~nm}$ and (b) $\lambda_{\text {las }}=476.5 \mathrm{~nm}$ are shown.

Term energies of the upper $\left(\mathcal{T}^{\prime}\right)$ and the teminating $\left[\mathcal{T}^{\prime \prime}\left(v_{i}^{\prime \prime}, J^{\prime \prime}\right)\right]$ levels and the line wave numbers $E_{\mathrm{f}}^{(i)}$ are related by

$$
\mathcal{T}^{\prime}=\mathcal{T}^{\prime \prime}\left(v_{i}^{\prime \prime}, J^{\prime \prime}\right)+E_{\mathrm{f}}^{(i)},
$$

where $i=1,2 \ldots$ denotes the observed lines belonging to the series. Similarly, the ground state $\left(v_{0}^{\prime \prime}, J_{0}^{\prime \prime}\right)$ level depleted by the laser liglit of wave number $E_{\text {las }}$ is found from

$$
\mathcal{T}^{\prime \prime}\left(v_{0}^{\prime \prime}, J_{0}^{\prime \prime}\right)=\mathcal{T}^{\prime \prime}\left(v_{i}^{\prime \prime}, J^{\prime \prime}\right)+E_{\mathrm{f}}^{(i)}-E_{\mathrm{las}}
$$

with $J_{0}^{\prime \prime}-J^{\prime \prime}=0, \pm 2$ depending on the branch of the transition. $\mathcal{T}^{\prime \prime}\left(v_{i}^{\prime \prime}, J^{\prime \prime}\right)$ is computed as a Dunham-like expansion in $\left(v_{i}^{\prime \prime}+1 / 2\right)$ and $\left[J^{\prime \prime}\left(J^{\prime \prime}+1\right)\right][22]$. The assignments of $\mathcal{T}^{\prime}, v_{0}^{\prime \prime}, J_{0}^{\prime \prime}$ and $v_{i}^{\prime \prime}(i=1,2 \ldots)$ are reached for each progression [20] following the application of a least-squares procedure based on Eqs. (6), (7). Satisfactory agreement with respective $\left(\lambda_{\text {las }}=465.8,472.7,476.5 \mathrm{~nm}\right)$ results of Amiot was obtained.

We established that the absorption occurs mainly from a few lowest vibrational levels of the ground state, $\mathcal{T}^{\prime \prime}=0 \div 700 \mathrm{~cm}^{-1}$ and the energies $\mathcal{T}^{\prime}$ of excited levels range from 21000 to $22500 \mathrm{~cm}^{-1}$, which is above the known part of (3) ${ }^{1} I_{\mathrm{u}}$. The green fluorescence at and in the vicinity of $522 \mathrm{~nm}$ terminates on the ligher levels of the ground state $\left(v^{\prime \prime}=50 \div 90\right.$ depending on $\left.\lambda_{\text {las }}\right)$. In some cases the Franck-Condon effects are observed, where every second or every third line is strong while the others are weak or invisible. In particular for $\lambda_{\text {las }}=457.9 \mathrm{~nm}$ 

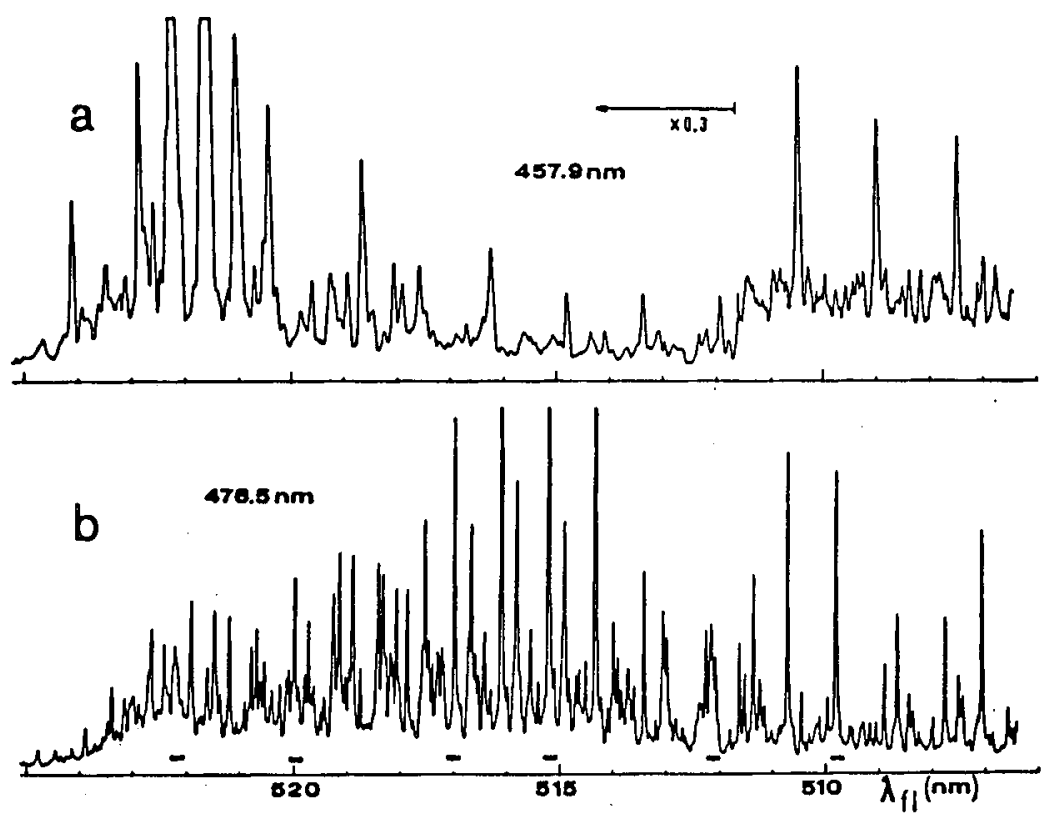

Fig. 8. Two selected portions of fluorescence spectra excited with (a) $\lambda_{\text {as }}=457.9 \mathrm{~nm}$ and (b) $\lambda_{\text {las }}=476.5 \mathrm{~nm}$. The bars drawn above the $\lambda_{\Omega}$ axis in (b) denote the regions ("windows") covered in the lifetime measurement described in Sec. 4.2.

one strong $Q$ progression dominates, for which in the range $\lambda_{\mathrm{fi}}=501 \div 518 \mathrm{~nm}$ every second line is significantly stronger. 'This observation correlates well with the earlier discussion of the weak bands excited with $\lambda_{\text {las }}=459.7 \mathrm{~nm}$ (Sec. 3.1.1).

The segment of the upper potential responsible for the green emission was reconstructed on the basis of the classical Franck-Condon approach [25]. The strongest line in the green portion of each progression was assumed to be connected with a "vertical" (constant $R$ ) transition between the outer turning points of both potentials. The terminating level of this transition and the corresponding value of $R$ are known from the analysis and from the known [22] $X^{1} \Sigma_{\mathrm{g}}^{+}$potential, respectively. The observed wave number was corrected for contribution due to the molecular rotation. As a result one of the outer turning points of the upper state could be drawn on the potential energy diagram. An analysis of several progressions excited with different laser lines provided points depicted in Fig. 9 . All points come from the analysis of series forming the structure at $522 \mathrm{~nm}$ except for full circles which originate from the analysis of the $476.5 \mathrm{~nm}$ excited transitions constituting the $515-519 \mathrm{~nm}$ region (the strong bands, see Sec. 3.1.1). In line with Ref. [12] we find that at least the intense lines in that region belong to the $E^{\prime}(3)^{1} \Pi_{\mathbf{u}} \rightarrow X^{1} \Sigma_{\mathrm{g}}^{+}$system. It can be seen that within the estimated errors of $100 \mathrm{~cm}^{-1}$ the points provide an extension of the $E^{\prime}(3)^{1} \Pi_{\mathrm{u}}$ potential towards higher internuclear distances. The known portions of the $E^{\prime}(3)^{1} \Pi_{\mathrm{u}}$ and the $E(3){ }^{1} \Sigma_{\mathrm{g}}^{+}$po- 


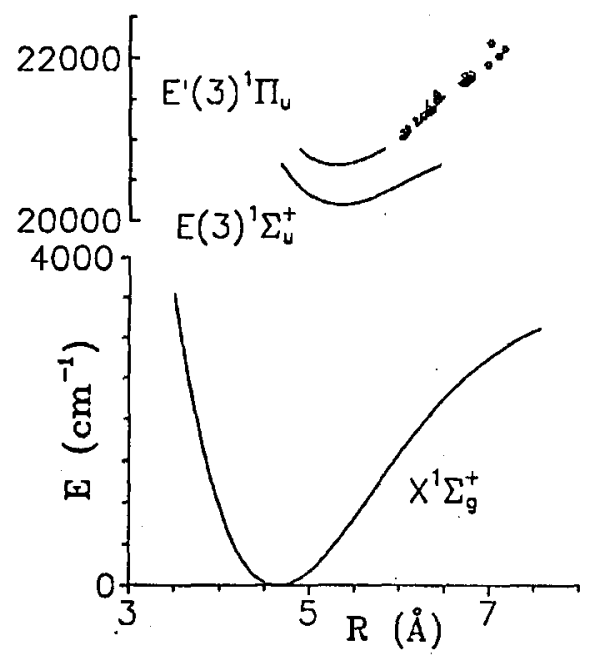

Fig. 9. Potential energy curves for the $X^{1} \Sigma_{\mathrm{g}}^{+}, E(3)^{1} \Sigma_{\mathrm{u}}^{+}$and $E^{\prime}(3){ }^{1} \Pi_{\mathrm{u}}$ electronic states of $\mathrm{Cs}_{2}$ (solid lines). The points follow the shape which represents a natural extension of the $E^{\prime}(3)^{1} \Pi_{\mathrm{u}}$ potential. The full circles and the triangles come from an analysis of fluorescence excited by $\lambda_{\text {las }}=476.5 \mathrm{~mm}$; the squares are for $472.7 \mathrm{~nm}$; the rhombi for $465.8 \mathrm{~nm}$; the stars for $457.9 \mathrm{~nm}$. Estimated uncertainty of energy amounts to $\pm 100 \mathrm{~cm}^{-1}$.

tentials [11,12] are drawn with solid lines. Also a portion of the $X^{1} \Sigma_{\mathrm{g}}^{+}$state is depicted.

In conclusion, the strong bands, the weak bands and the structure at $522 \mathrm{~nm}$ belong to the $E^{\prime}(3)^{1} \Pi_{\mathrm{u}} \rightarrow X^{1} \Sigma_{\mathrm{g}}^{+}$system.

\section{Decay dynamies}

\subsection{Lifetime measurements will the pulsed dye laser}

Time-resolved fluorescence excited with $\lambda_{\text {las }}=463.4 \mathrm{~nm}$ was observed (for the apparatus see Fig. 2) at the maximum of the $522 \mathrm{~nm}$ band for different temperature settings. $\lambda_{\text {las }}$ was chosen among those at which the $522 \mathrm{~nm}$ band clearly dominates over accompanying spectral structures. Cell temperatures were varied over the ranges $T_{1}=469 \div 553 \mathrm{~K}$ and $T_{2}=476 \div 564 \mathrm{~K}$, while the difference $T_{2}-T_{1}$ was kept nearly constant. The corresponding number densities amount to $n_{\text {at }}=(0.15 \div 2.2) \times 10^{16} \mathrm{~cm}^{-3}$ and $n_{\mathrm{mol}}=(0.026 \div 1.2) \times 10^{14} \mathrm{~cm}^{-3}$ for atoms and molecules, respectively [26]. Due to non-selective conditions $\left(\Delta \lambda_{\text {las }}=10 \mathrm{~cm}^{-1}\right.$, $\Delta \lambda_{\mathrm{f}}=80 \mathrm{~cm}^{-1}$ ) several excited levels participate in the observad fluorescence. We anticipate that their lifetimes can differ considerably (e.g. due to perturbations) and therefore that decay curves are described by a sum of exponentials

$$
I(t)=\sum_{i} C_{i} \exp \left(-t / \tau_{i}^{\mathrm{eff}}\right)
$$


where $\tau_{i}^{\text {eff }}$ denotes the weighted a verage of the effective, i.e. temperature-dependent lifetimes in the $i$-th distinct group of simultaneously excited levels with similar decay properties.

A deconvolution procedure combined with a least-squares method was used to recover decay constants from the decay plots. The laser pulse shape was determined with the same detection system; the instrumental time response resulted in FWHM of $6 \mathrm{~ns}$ for the measured pulse. The most reliable fits were reached with trial functions (Eq. (8)) consisting of two exponentials. (Iowever, the possible role of the third unresolved fast component, with $\tau_{3}^{\text {eft }} \leq 1 \mathrm{~ns}$, is not excluded. Indeed in more accurate measurements (Sec. 4.2) three decay components were separated.)

Computer simulations based on a rate equations model were performed. They showed that the two involved groups of levels, characterized by the faster and the slower decay, are at most weakly coupled by collisions [18].

Extrapolation of the decay parameters $1 / \tau_{i}^{\text {eff }}$ to the collisionless limit was performed with the Stern-Volmer formula delivering lifetimes $\tau_{1}, \tau_{2}$ and depopulation cross-sections $\sigma_{1}, \sigma_{2}$. The results are presented in Table I(a). Errors in parenthesis are in units of the last quoted digit.

TABLE I

Results of lifetime measurements with deconvolution into two decay components: (a) lifetimes $\tau_{1}, \tau_{2}$ extrapolated to zero density and quenching cross-sections $\sigma_{1}, \sigma_{2}$ for $\lambda_{\text {las }}=463.4 \mathrm{~nm}$ and $\lambda_{\mathrm{f}}=522 \mathrm{~nm}$; (b) effective lifetimes $\tau_{1}^{\text {eff }}, \tau_{2}^{\text {eff }}$ for sevcral $\lambda_{\text {las }}$ and $\lambda_{\mathrm{n}}$ (temperature $T_{1}=553 \mathrm{~K}$ ).

(a)

\begin{tabular}{c|c|c|c}
\hline \hline$\tau_{1}(\mathrm{~ns})$ & $\sigma_{1}\left(\AA^{2}\right)$ & $\tau_{2}(\mathrm{~ns})$ & $\sigma_{2}\left(\AA^{2}\right)$ \\
\hline $25(6)$ & $1400(300)$ & $2.6(4)$ & $2300(3000)$ \\
\hline
\end{tabular}

(b)

\begin{tabular}{lr|r|r|c|r|r|r}
\hline \hline $\begin{array}{l}\lambda_{\mathrm{f1}} \\
(\mathrm{nm})\end{array}$ & $\begin{array}{r}\lambda_{\text {las }} \\
(\mathrm{nm})\end{array}$ & 461.1 & 463.4 & 466.7 & 470.6 & 472.3 & \multicolumn{1}{c}{477.1} \\
\hline 508.9 & $7.1 \backslash 1.6$ & $7.6 \backslash 1.8$ & $-\backslash-$ & $8.9 \backslash 2.0$ & $10.2 \backslash 3.3$ & $10.1 \backslash 3.0$ \\
516.1 & $6.3 \backslash 1.2$ & $7.8 \backslash 2.0$ & $8.4 \backslash 1.9$ & $9.0 \backslash 2.5$ & $9.6 \backslash 3.1$ & $9.4 \backslash 2.7$ \\
518.2 & $6.3 \backslash 1.2$ & $7.6 \backslash 2.0$ & $9.1 \backslash 2.2$ & $9.0 \backslash 2.6$ & $9.4 \backslash 2.7$ & $9.9 \backslash 3.0$ \\
522.4 & $6.1 \backslash 1.7$ & $7.5 \backslash 2.2$ & $8.8 \backslash 2.2$ & $7.5 \backslash 1.9$ & $9.4 \backslash 2.8$ & $8.5 \backslash 2.3$
\end{tabular}

In Table I(b) there are effective lifetimes $\tau_{1}^{\text {eff }}, \tau_{2}^{\text {efr }}$ determined at a single temperature setting $\left(T_{1}=553 \mathrm{~K}, T_{2}=564 \mathrm{~K}\right)$ but for several selected excitation and fluorescence wavelengths. The estimated accuracy is $0.5 \mathrm{~ns}$. Both lifetimes are noted to gradually shorten with decreasing $\lambda_{\text {las }}$.

\subsection{Lifetime measuremenls wilh the mode-locked argon ion laser}

The laser was set at $\lambda_{\text {las }}=476.5 \mathrm{~nm}$. The monochromator was tuned consecutively to $\lambda_{\mathrm{fl}}=500.0,509.8,512.1,515.2,517.0,519.9$ and $522.2 \mathrm{~nm}$. In Fig. $8 \mathrm{~b}$ 
horizontal bars below the spectrum indicate the $6 \mathrm{~cm}^{-1}$ fluorescence bandwidth ranges covered in these measurements. The measurements were performed with the apparatus shown in Fig. 4, for several lieat-pipe oven temperatures in the range of 514-579 K. The procedure of Sec. 4.1 was applied in the analysis. The laser pulse of $0.8 \mathrm{~ns}$ duration was measured by the detection system as $2.5 \mathrm{~ns}$ long due to the instrumental time response. It turned out that at least three exponential components (Eq. (8)) have to be included for a satisfactory fit. Extrapolation with the Stern-Volmer formula gave two longer lifetimes $\tau_{1}$ and $\tau_{2}$. Also deactivation cross-sections $\sigma_{1}, \sigma_{2}$ were obtained. No reliable analysis of the fastest component could be performed except for an estimate $\tau_{3} \leq 1 \mathrm{~ns}$.

Table II gathers the results of this section. These can be compared with the lifetimes reported in Sec. 4.1. The larger value from Table Ia is close to $\tau_{1}$ of Table II, while the smaller one corresponds to a combination of $\tau_{2}$ (of Table II) and $\tau_{3}$, which were not differentiated in Sec. 4.1. Consistency between our lifetime results and those cited in Sec. 1 was discussed in Ref. [19].

\subsection{Discussion of the lifetime results and estimation of the predissociation rate}

The multiexponential decays reported in this paper are interpreted as a result of the influence of perturbing states. Since potential calculations for $\mathrm{Cs}_{2}$ are restricted to the lowest states [2] the inferences regarding perturbing states can only be drawn indirectly; e.g. by a cautious comparison with the results for the closely related molecule $\mathrm{Rb}_{2}[27,28]$.

Spiegelman et al. [28] performed cxtensive calculations for $\mathrm{Rb}_{2}$. Adapting their results to the case of $\mathrm{Cs}_{2}$, it secms reasonable that heterogeneous perturbation observed from the very bottom of the $E^{\prime}(3)^{1} I_{\mathrm{u}}$ potential [12] is induced by the $E(3)^{1} \Sigma_{\mathrm{u}}^{+}$state. Candidates for the states inducing homogeneous perturbations revealed in Ref. [12] are $(3)^{3} \Sigma_{\mathrm{u}}^{+}$correlated with $\left(5^{2} D+6^{2} S\right)$ atoms, $(4)^{3} \Sigma_{\mathrm{u}}^{+}$ correlated with $\left(7^{2} S+6^{2} S\right)$ atoms as well as $(3)^{3} I_{\mathrm{u}}$ correlated with $\left(7^{2} P+6^{2} S\right)$ atoms which probably closely follows the shape of $E^{\prime}(3)^{1} / I_{\mathrm{u}}$. Efficient production of $\mathrm{Cs}\left(5^{2} D\right)$ with a maximum for $474 \mathrm{~nm}$ excitation, reported by Collins et al. [13], is due to predissociation by the (3) ${ }^{3} \Sigma_{\mathrm{u}}^{+}$state which probably joins the left limb of the $E^{\prime}$. As can be deduced by correlating the results of Refs. [14] and [12], levels in the $v^{\prime}=10 \div 20$ range are most affected by interaction with (3) ${ }^{3} \Sigma_{u}^{+}$. The pronounced population of $\mathrm{Cs}\left(7^{2} S\right)$ after excitation witl $465.8 \mathrm{~nm}$ line reported by Wu and Huennekens can be due to perturbation of high enough levels by the $E(3)^{1} \Sigma_{\mathrm{u}}^{+}$ and the (4) ${ }^{3} \Sigma_{\mathrm{u}}^{+}$states. (Ilowever, direct photodissociation of the $E(3)^{1} \Sigma_{\mathrm{u}}^{+}$state might also be responsible for production of $\mathrm{Cs}\left(7^{2} S\right)$ [15].) Finally, the (2) ${ }^{3} \Sigma_{\mathrm{u}}^{+}$ state correlated with $\left(6^{2} P+6^{2} S\right)$ atoms can predissociate $E^{\prime}$ leading to inefficient production of $6^{2} P$ atoms observed in Refs. $[13,14]$.

The above-mentioned interactions can influence lifetimes of levels. The lifetimes of such perturbed levels can, in general, be shortened or prolonged [29-32] as relative to those of unperturbed levels. For example in multiexponential decays of the $C(2)^{1} \Pi_{\mathrm{u}}$ state of $\mathrm{Cs}_{2}$, the two shorter lifetimes were attributed to levels predissociating via a repulsive triplet state [29]. Similar interpretation was also established for the $D(2)^{1} \Sigma_{\mathrm{u}}^{+}$state [30]. 
TABLE II

Results of lifetime measurements for $\lambda_{\text {las }}=476.5 \mathrm{~nm}$ at several $\lambda_{\mathrm{f}}$. Three decay components were assumed. Lifetimes $\tau_{1}, \tau_{2}$ and quencling cross-sections $\sigma_{1}, \sigma_{2}$ are listed. For the shortest lifetime an estimate $\tau_{3} \leq 1$ ns was found.

\begin{tabular}{c|l|c|c|c}
\hline \hline$\lambda_{\mathrm{fl}}(\mathrm{nm})$ & $\tau_{1}(\mathrm{~ns})$ & $\sigma_{1}\left(\AA^{2}\right)$ & $\tau_{2}(\mathrm{~ns})$ & $\sigma_{2}\left(\AA^{2}\right)$ \\
\hline 500.0 & $35(8)$ & $1200(200)$ & - & - \\
509.8 & $33(12)$ & $1200(300)$ & $5.0(10)$ & $1900(700)$ \\
512.1 & $25(8)$ & $900(400)$ & $3.0(20)$ & $1200(1000)$ \\
515.2 & - & - & $4.4(5)$ & $1200(500)$ \\
517.0 & - & - & $5.0(10)$ & $1800(700)$ \\
519.9 & $26(8)$ & $1100(300)$ & $6.0(10)$ & $1900(900)$ \\
522.2 & $29(10)$ & $1000(400)$ & $6.0(20)$ & $2000(1300)$
\end{tabular}
as follows:

Two possible interpretations of lifetime results of Table II can be postulated

(1) The medium lifetime $\tau_{2}$ is associated with unperturbed levels of the $E^{\prime}(3)^{1} \Pi_{\mathrm{u}}$ state and the longer lifetime $\tau_{1}$ with levels perturbed by the long-lived state (supposedly (3) ${ }^{3} \Pi_{\mathrm{u}}$ ). The shortest lifetime $\tau_{3} \leq 1$ ns can be associated with predissociating levels. Since the measured lifetime is related to the radiative decay rate $\Gamma_{\mathbf{r}}$ and the predissociation rate $\Gamma_{\mathrm{p}}$ :

$$
1 / \tau=\Gamma_{\mathrm{r}}+\Gamma_{\mathrm{p}}
$$

hence, an estimate based on Eq. (9) gives $\Gamma_{\mathrm{p}} \geq 700 \mu \mathrm{s}^{-1}$ for predissociating levels.

(2) An alternative possibility is that the longer lifetime $\tau_{1}$ is close to the natural lifetime of unpcrturbed levels while the two shorter ones are connected with predissociated levels. With this assumption one gets from Eq. (9) $\Gamma_{\mathbf{p}} \cong$ $200(100) \mu \mathrm{s}^{-1}$ for a group of medium predissociated levels (characterized by $\tau_{2}$ ) and $\Gamma_{\mathrm{p}} \geq 1000 \mu \mathrm{s}^{-1}$ for a group of stronger predissociated levels (characterized by $\left.r_{3}\right)$.

The estimates can be compared with other data for $\mathrm{Cs}_{2}$. From lifetimes for $C(2)^{1} \Pi_{\mathrm{u}}$ (red excitation) reported by Katô et al. [29] one can deduce: $\Gamma_{\mathrm{p}} \cong$ $260 \mu \mathrm{s}^{-1}$ and $\Gamma_{\mathrm{p}} \cong 1930 \mu \mathrm{s}^{-1}$, for weaker and stronger predissociated levels, respectively. Bieniak et al. [30] reported $\Gamma_{\mathrm{p}}=45 \div 323 \mu \mathrm{s}^{-1}$ for $D(2)^{1} \Sigma_{\mathrm{u}}^{+}\left(v^{\prime}=43\right.$, $J^{\prime}=92 \div 129$ ) levels (yellow excitation) assuming the unperturbed lifetime of $18 \mathrm{~ns}$. Recently, for $C(2)^{1} \Pi_{\mathrm{u}}$, a weak predissociation $\Gamma_{\mathrm{p}} \leq 30 \mu \mathrm{s}^{-1}$, with a maximum for $\boldsymbol{v}^{\prime}=\mathbf{3}$ was estimated from the linewidth considerations of Baba et al. [33]. With the same method $\Gamma_{\mathrm{p}} \cong 1000 \mu \mathrm{s}^{-1}$ was determined for the $D(2)^{1} \Sigma_{\mathrm{u}}^{+}\left(v^{\prime}=46\right.$, $J^{\prime}=30 \div 70$ ) levels by Katô et al. [34]. The blue light induced predissociation of $\mathrm{Cs}_{2}$ towards $6^{2} P$ and $5^{2} D$ atoms is stronger than that excited with any longer wavelength in the visible. It can be even more pronounced due to the presence of a channel towards $7^{2} S$. (See review in Sec. 1, Fig. 1 in Ref. [14] and Ref. [15].) Thus our estimates of $\Gamma_{\mathrm{p}}$ are consistent with the data for other spectral regions. 
In Ref. [15], the total predissociation rates are given for the blue (and green) excitation range, they amount to 33,16 and $9 \mu \mathrm{s}^{-1}$ for excitation of $465.8,488.0$ and $514.5 \mathrm{~nm}$, respectively. In order to obtain these rates, the authors of Ref. [15] scaled the relative predissociation rates with lifetimes measured with a method assuming single exponential decay. This scaling gave also radiative lifetimes: 370 , 130 and $125 \mathrm{~ns}$ (for respective wavelengths) which exceed significantly $\tau_{1} \cong 30 \mathrm{~ns}$ considered by us as an unperturbed (if not prolonged) lifetime.

Since, particularly for the $465.8 \mathrm{~nm}$ excitation, it could be expected that the overall dynamic characteristics of fluorescence is similar to that for the $476.5 \mathrm{~nm}$ excitation of Sec. 4.2 (in both cases neighboring regions of the $E^{\prime}(3)^{1} I_{\mathrm{u}}$ potential are involved) the discrepancies with our results require some explanation. They appear to originate in the value taken in Ref. [15] for scaling. The approach of Ref. [15] was based on an implicit assumption that all excited levels predissociate with the same average rate. This approximation seems to be too rough in view of the disclosed fact that the spectrally broad fluorescence of $E^{\prime}$ decays with several different lifetimes. We performed scaling of the relative predissociation rates (with Eq. (31) and data from Tables I and III of Ref. [15] for the $465.8 \mathrm{~nm}$ excitation) with our lifetimes $\tau_{2}$ and $\tau_{3}$. This resulted in the total predissociation rates of the order of hundreds of $\mu \mathrm{s}^{-1}$ and radiative lifetimes of, at most, some tens of nanoseconds. These values of the predissociation rates are now quite close to our estimates based on lifetimes of the present paper only.

\section{Summary of the results}

We have presented the results of a scrics of experiments aimed at studying the origin and dynamic properties of the green $\mathrm{Cs}_{2}$ fluorescence excited by blue laser light.

The analysis has shown that the observed fluorescence originates in the directly excited levels rather than in levels populated in collisional transfer (also intersystem), or due to cascading from higher states. The absorbing levels have been attributed to the bottom part of the $X^{1} \Sigma_{\mathrm{g}}^{+}$potential. From the initial considerations it was established that $E^{\prime}(3)^{1} I I_{\mathrm{u}}$ is a candidate for the upper state of the observed transitions. Indeed the reconstructed portion of the potential curve responsible for the observed fluorescence (Fig. 9) constitutes a natural extension of the $E^{\prime}(3)^{1} \Pi_{\mathrm{u}}$ state. The $522 \mathrm{~nm}$ band and the weak bands discussed in Sec. 3.1.1 originate in the energy range where the attractive branch of the $E^{\prime}(3)^{1} \Pi_{\mathrm{u}}$ state potential runs almost parallel to that of $X^{1} \Sigma_{\mathrm{g}}^{+}$(which corresponds to minimum in the difference potential). Since the main contribution to the transition probability comes from internuclear distances close to the classical turning points of the vibrating oscillator, several lines originating in the vicinity of the outer turning points in levels situated in the above-defined energy region have close wave numbers and sum up [35] forming a structure observed under low resolution as the $522 \mathrm{~nm}$ band. With a similar interpretation of the absorption peak at $522 \mathrm{~nm}$ by Tellinghuisen and Moeller [7], we conclude that the same system of levels is involved in both fluorescence and absorption. The strong bands of Sec. 3.1.1 originate in the lower levels of the excited state, where branches are no longer parallel and difference potential increases. 
The obtained lifetime values are gatlicred in Tables I and II and discussed in Sec. 4.3. The multiexponential decay signals of fluorescence are interpreted as evidence of perturbations of the $E^{\prime}(3)^{1} I_{u}$ state by a number of bound and repulsive states of different symmetry. Estimates of predissociation rates give values of at least hundreds of $\mu \mathrm{s}^{-1}$. The cross-sections for quenching of the $E^{\prime}(3)^{1} \Pi_{\mathrm{u}}$ state of $\mathrm{Cs}_{2}$ by collisions with Cs atoms are also obtained.

\section{Acknowledgments}

The authors acknowledge constant interest and advice of late Prof. K. Rosiński. The authors are indebted to Dr. P. Kowalczyk for performing computations helpful in the early stage of the experiment.

\section{References}

[1] C. Amiot, W. Demtröder, C.R. Vidal, J. Chem. Phys. 88, 5265 (1988).

[2] G.H. Jeung, F. Spiegelmann, J.P. Daudey, J.P. Malricu, J. Phys. B 16, 2659 (1983); M. Krauss, W.J. Stevens, J. Chem. Phys. 03, 4236 (1990).

[3] J.M. Walter, S. Barratt, Proc. R. Soc. Lond. A 119, 257 (1928).

[4] F.W. Loomis, P. Kusch, Phys. Rev. 46, 292 (1931).

[5] M. Lapp, L.P. Harris, J. Quant. Spectrosc. Radiat. Transf. 6, 169 (1966).

[6] R. Gupta, W. Happer, J. Wagner, E. W'inniayr, J. Chem. Phys. 68, 799 (1978).

[7] J. Tellinghuisen, M.B. Moeller, Chem. Phys. 50, 301 (1980).

[8] H. Katô, K. Yoshihara, J. Chem. Pliys. 71, 1585 (1979).

[9] B. Bieniak, M. Glódź, W. Jastrzębski, Phys. Letl. A 120, 171 (1988).

[10] C. Amiot, C. Crépin, J. Vergès, Chem. Phys. Lett. 08, 608 (1983).

[11] C. Amiot, C. Crépin, J. Vergès, J. Mol. Spcctrosc. 107, 28 (1984).

[12] C. Amiot, J. Chem. Phys. 89, 3993 (1988).

[13] C.B. Collins, J.A. Anderson, D. Popescu, Lovitzu Popescu, J. Chem. Phys. 74, 1053 (1981).

[14] C.B. Collins, F.W. Lee, J.A. Anderson, P.A. Vicharelli, D. Popescu, Iovitzu Popescu, J. Chem. Phys. 74, 1067 (1981).

[15] Z. Wu, J. Huennekens, J. Chem. Phys. 81, 4433 (1984).

[16] G. Baumgartner, W. Demtröder, M. Stock, Z. Phys. 232, 462 (1970).

[17] G. Höning, M. Czajkowski, M. Stock, W. Demtröder, J. Chem. Phys. 71, 2138 (1979).

[18] B. Bieniak, M. Głódź, W. Jastrzębski, Acła Phyys. Pol. A 78, 305 (1990).

[19] B. Bieniak, J. Szonert, Phys. Lett. A 152, 47 (1991).

[20] J. Szonert, B. Bieniak, Acla Phys. Pol. A 79, 789 (1991).

[21] B. Bieniak, P. Filipowicz, M. Głódź, W. Jastrzębski, J. Szonert, T. Witwicki, Opt. Appl. 17, 39 (1987); B. Bicniak, M. Głódż, W. Jastrzębski, Opt. Appl. 18, 319 (1988).

[22] H. Weickenmeier, U. Diemer, M. Wahl, M. Raab, W. Demtröder, W. Müller, J. Chem. Phys. 82, 5354 (1985). 
[23] U. Diemer, J. Gress, W. Demtröder, Chem. Phys. Lett. 178, 330 (1991).

[24] D.L. Drummond, L.A. Schlie, J. Chenn. Phys. 65, 2116 (1976); N. Allard, J. Kielkopf, Rev. Mod. Phys. 54, 1103 (1982).

[25] G. Herzberg, Molecular Spectra and Molecular Structure, Vol. 1, Spectra of Diatomic Molecules, Van Nostrand, Princeton 1955, p. 193.

[26] A.N. Nesmeyanov, Vapor Pressure of the Elcments, Elsevier, New York 1963.

[27] E.J. Breford, F. Engelke, Chem. Phys. Lelt. 75, 132 (1980).

[28] F. Spiegelmann, D. Pavolini, J.P. Daudey, J. Phys. B 22, 2465 (1989).

[29] H. Katô, K. Yokoyama, M. Baba, N. Tamai, I. Yamazaki, S. Nagakura, J. Chem. Phys. 87, 1987 (1987).

[30] B. Bieniak, H.P. Hinske, II. Paulus, D. Zevgolis, W. Demtröder, Ann. Phys. (Leipzig) 48, 15 (1991).

[31] G. Baumgartner, H. Kornmeier, W. Preuss, Chem. Phys. Lell. 107, 13 (1984); W. Preuss, G. Baumgartner, Z. Phys. A 320, 125 (1985).

[32] T. Uzer, A. Dalgarno, Chem. Phys. 51, 271 (1980).

[33] M. Baba, T. Nakahori, T. Iida, I. Kałô, J. Chem. Phys. 93, 4637 (1990).

[34] H. Katô, T. Kobayashi, M. Clıosa, T. Nakalıori, T. Iida, S. Kasalıara, M. Baba, J. Chem. Phys. 94, 2600 (1991).

[35] R.S. Mulliken, J. Chem. Phys. 55, 309 (1971). 